\title{
De Hannah Arendt a Judith Butler: em busca da humanidade perdida nas fronteiras do estado-nação
}

\section{Hannah Arendt of Judith Butler: in search of the lost humanity border state nation}

\author{
Maiquel Angelo Dezordi Wermuth \\ Joice Graciele Nielsson ${ }^{* *}$
}

\section{Resumo}

O objetivo deste trabalho é refletir sobre a condição dos refugiados no mundo atual, a partir da obra de Hannah Arendt e Judith Butler. As reflexões de Arendt, ao fim da Segunda Guerra, feitas a partir da condição dos refugiados, excluídos das fronteiras estatais, resultaram em um alerta para a necessária desvinculação entre a proteção jurídico-política dos seres humanos e sua vinculação, enquanto cidadãos, com determinado Estado-nação. Tal alerta conduziu a uma ruptura de conceitos tradicionais da filosofia política, como cidadania, Estados e direitos humanos, recepcionada e tida como impulsionadora da construção de um aparato jurídico-político de proteção dos direitos humanos em âmbito internacional sem precedentes na história. Passados mais de setenta anos, novamente o refugiado coloca em cheque tal aparato, e o mundo continua a se mostrar incapaz de efetivar a proteção da vida humana de modo desvinculado da fronteira estatal. É neste sentido que Butler desenvolve seus estudos. Para a autora, as fronteiras (bio)políticas atuais continuam a cindir o mundo entre vidas abjetas e vidas que merecem ser vividas, embora agora não sejam apenas físicas, mas também simbólicas ou culturais e precisam ser, urgentemente, des/ re-construídas performaticamente ou profanadas. A presente pesquisa utilizará o método fenomenológico-hermenêutico, a partir da constatação de que os

Doutor em Direito pela Universidade do Vale do Rio dos Sinos - Unisinos. Professor dos cursos de graduação em Direito da Unisinos e da Universidade Regional do Noroeste do Estado do Rio Grande do Sul - Unijuí. Professor do Curso de Mestrado em Direitos Humanos da Unijuí. ljuí - RS - Brasil. E-mail: madwermuth@gmail.com.

* Doutoranda em Direito Público pela Unisinos. Professora do Curso de Graduação em Direito da Unijuí. ljuí - RS - Brasil. E-mail: joice.gn@gmail.com. 
sujeitos (autores do artigo) estão inseridos no mundo no qual os movimentos migratórios contemporâneos ocorrem, sendo direta e indiretamente afetados por eles, e justamente nesta intercessão, e não em alguma espécie de cisão, é que reside o significado do fenômeno.

Palavras-chave: Estado-nação. Fronteiras. Humanidade. Refugiados.

\section{Abstract}

The objective of this paper is to discuss the condition of refugees in the world today, from the work of Hannah Arendt and Judith Butler. The reflections of Arendt, at the end of World War II, made from the condition of refugees, excluded from state borders resulted in an alert to the necessary separation between the legal and political protection of human beings and their relationship, as citizens, with particular nation-state. Such alert led to a break from traditional concepts of political philosophy, such as citizenship, States and human rights, type approved and seen as driving the construction of a legal and political apparatus of protection of human rights internationally, unprecedented in history. After more than seventy years, again refugee puts in check such apparatus, and the world continues to prove unable to carry out the protection of human life unbound mode of the state border. In this sense, Butler develops her studies. For the author, the boundaries (bio) current policies continue to divide the world into abject lives and lives that deserve to be lived, though now are not only physical but also symbolic or cultural and need to be urgently des-re-built performatively or desecrated. This research will use the phenomenological-hermeneutical method, from the fact that the subject (article's authors) are entered into the world in which contemporary migratory movements take place, and directly and indirectly affected by them, and precisely in this intercession, and not in some sort of spin-off, is lies the significance of the phenomenon.

Keywords: Nation-state. Borders. Humanity. Refugees.

\section{Introdução}

Deslocamentos humanos, embora tenham sido constantes na história da humanidade, têm se intensificado cada vez mais no atual cenário geopolítico mundial, desafiando as fronteiras que dividem $o$ 
mundo em Estados-nação desde a Modernidade. Neste mundo cindido física, simbólica e/ou culturalmente -, o avanço de um contingente cada vez maior de pessoas que não sabem ao certo de onde vêm nem para onde vão, se chegarão ou se ficarão pelo caminho, o que encontrarão e o que não - e, fundamentalmente, o que são (seres abjetos?) e o que não são (humanos?) -, tem desafiado a capacidade das categorias da filosofia política tradicional em dar conta dessa realidade complexa.

Este artigo analisa tal fenômeno a partir das propostas críticas de duas grandes filósofas, cujas obras encontram-se separadas por um considerável lapso temporal: Hannah Arendt e Judith Butler. Arendt, há setenta anos, alertava ao mundo de que a vinculação entre humanidade, ou melhor, a proteção dada ao ser humano contida no conceito de cidadania, e seu pertencimento a determinado Estado-nação, deixava à margem de tal proteção justamente o humano que dela mais necessitava. Tal paradoxo, representado na figura do refugiado, apontava, segundo a autora, para uma ruptura e uma necessária reconfiguração de categorias fundamentais como Estado-nação, cidadania e direitos humanos.

Novamente, no cenário (bio)político atual, em que a produção da vida nua, da vida abjeta, da cisão entre vidas que valem a pena ser vividas e vidas descartáveis se intensifica, a categoria do refugiado (que pode ser tanto o que é expulso, como o que está preso na própria armadilha da fronteira nacional) se coloca diante desse complexo e o faz ruir. O que aprendemos com o legado de Hannah Arendt? Muito pouco, parece nos dizer Judith Butler. Seus estudos, no século seguinte ao de Arendt, apontam para o mesmo caminho, para a mesma necessidade pulsante de des/re-construção das categorias que continuam a aprisionar (ou a expulsar) os seres humanos que mais precisam da condição de humanidade necessária ao alcance da proteção jurídico-política no mundo atual.

Tal mundo, paradoxalmente cada vez mais interconectado, cada vez mais próximo (uma communitas) e, por isso mesmo, cada vez mais dividido por uma série de fronteiras que dividem a vida humana, representa o avanço da biopolítica e do paradigma imunizatório, segundo 
o filósofo italiano Roberto Esposito. E, neste cenário complexo, paradoxal e biopolítico, a proposta de Butler, de desconstrução performativa de categorias que busquem identificar a priori o que seria o humano e aprisionar a humanidade dentro de tais fronteiras físicas, simbólicas ou culturais, conduziria à profanação, no sentido proposto pelo filósofo italiano Giorgio Agamben, do próprio conceito de Estado, mas também da nação e, porque não, do próprio conceito de humanidade. Eis o problema que conduz a presente investigação.

Parte-se da hipótese de que retomar essa tarefa e contribuir na sua construção (ou desconstrução) afigura-se como condição de possibilidade para a viabilização de estratégias de resistência às investidas do biopoder contemporâneo, que significam o estabelecimento de cesuras entre as vidas que merecem e as que não merecem ser vividas e, em últimos casos, até mesmo lamentadas. Em relação aos refugiados, isso significa o pensar de uma forma de considerá-los "tal qual são", sem esperar que cumpram com esta ou aquela função no contexto de uma determinada sociedade. Em outras palavras: significa viabilizar que eles sejam "potencialidades", que sejam reconhecidos por sua própria humanidade, em detrimento de qualquer "rotulação" jurídica. Em síntese, busca-se realizar uma reflexão sobre alternativas que signifiquem a resolução do nexo entre lei e vida.

Utiliza-se, na investigação, o método fenomenológicohermenêutico, notadamente a partir das contribuições de Martin Heidegger e Hans-Georg Gadamer, a partir da constatação de que, enquanto sujeitos, estamos inseridos no mundo no qual os movimentos migratórios contemporâneos ocorrem, sendo direta e indiretamente afetados por eles. Aqui reside o significado do fenômeno.

A opção metodológica está assentada sobre a importância da linguagem

como todo entendimento que se realiza em palavras, um tal 'diálogo' não precisa apenas se ajustar ao campo de domínio da respectiva língua e de suas regulações. As coisas dãose muito mais de tal modo que a própria resposta impele para a palavra (GADAMER, 2007). 
Não se busca um estudo a partir do qual o sujeito esteja "afastado" ou "cindido" do seu objeto. Pelo contrário, o objeto e o sujeito são constituídos pela palavra e por meio dela recebem a atribuição de sentido - daí o aspecto hermenêutico.

Em linhas gerais, portanto, pode-se dizer que a contribuição da hermenêutica filosófica para a elaboração do presente artigo foi demonstrar que as condições que tornam o pensamento possível não são autogeradas, mas são estabelecidas bem antes de nos engajarmos em atos de introspecção, ou seja, que nós já estamos envolvidos no mundo bem antes de nos separarmos dele teoricamente para procurar entendê-lo filosoficamente. Não há, portanto, terminantemente, qualquer possibilidade de cisão entre sujeito e objeto.

\section{As fronteiras do Estado-nação: immunitas à violência da comunidade comum}

Desde a Modernidade, fronteiras e limites fazem parte da organização geopolítica do mundo. Sua necessidade remete, segundo Esposito (2013, p. 18), à falta de limites externos e internos característicos da comunidade originária, cujos habitantes, "os pecadores de Dante, os gigantes de Vico, os lobos de Hobbes", não estavam separados por nada capaz de os proteger reciprocamente. Portanto, expostos à condição comum de ser "nada mais-que-comunidade, comunidade nua, despojada/despida de toda forma", a violência poderia comunicar-se livremente, associando, desde cedo, comunidade original e violência.

Deste modo, a representação mítica da origem da violência não abala a comunidade desde o exterior, mas de seu interior, do coração do que lhe é "comum", levando Esposito (2013, p. 20) a concluir que é a excessiva igualdade, a carência de diferença e não seu excesso, que gera a violência recíproca fundante do contrato social. Em Hobbes (ESPOSITO, 2013, p. 20), por exemplo, "o que produz uma violência insuportável não é um acidente externo qualquer, mas a 
própria comunidade enquanto tal", vinculada à possibilidade comum de autodestruição, na qual se funda nossa igualdade primária. Em um contexto tal, "todos podem ser, indistintamente, carrascos e vítimas", e é esta igualdade que une a todos numa mesma condição. Não se trata, portanto, da diferença, mas da indiferença, o que coloca os homens literalmente nas mãos uns dos outros, gerando uma multidão indiferenciada destinada à autodestruição, tomada como justificativa à implantação das fronteiras.

Esta é a hipótese prévia dos grandes mitos fundacionais assumidos pela filosofia política moderna. Dominado pelo desejo ilimitado de tudo e pelo medo de ser morto, o homem original não pode senão destruirse, afinal, segundo Sartre (ESPOSITO, 2013, p. 12), "o inferno são os outros", isto é, os outros, a própria comunidade, são o inferno de cada "eu", numa espécie de "ausência de confins que torna impossível, mais do que a distinção entre seus membros, sua própria determinação". Ao cobrir todo o espaço da vida, esta não é determinável, definível segundo um princípio de identidade, nem para o exterior, nem em seu interior, distinção que, na verdade, não existe.

No discurso filosófico da Modernidade, enfim, nesta comunidade originária, sem limites, "a violência assume a forma fluída da contaminação", que se dá pelo sangue da primeira vítima que infecta a comunidade, arrastando-a para a violência recíproca. Pela falta de identidade, de individualidade, de diferença, é que o munus que nela circula livremente se transforma em veneno que transmite a morte. "Tanto fora do logos, do discurso, como do nomos, da lei, essa comunidade, precisamente antinômica, constitui uma ameaça insuportável para todos os seus membros" (ESPOSITO, 2013, p. 19).

Segundo Esposito (2013, p. 19), é precisamente contra a ameaça do contágio mortal da comunidade indiferenciada que a Modernidade criou, em suas dinâmicas reais e em sua autointerpretação, um enorme aparato de imunização. Para o autor, immunitas está em contraste direto com communitas: se a communitas se caracteriza pela livre circulação do munus, como dom e como veneno, ou como contato e contágio, 
a immunitas é aquilo que o desativa, reconstruindo novos confins protetores ao exterior do grupo e entre seus próprios membros. E se a communitas é inevitavelmente violência, seu immunitas é, a partir da Modernidade, precisamente a sua limitação: a fronteira.

Como bem explicou Carl Schmitt (2006), nomos tem como significado inicial a separação. Instaura-se gravando na terra a distinção, e inclusive a oposição, entre o "meu" e o "seu”, entre o "nosso" e o "vosso". Desde a sua origem, pode-se dizer que a civilização humana praticou o traçado de limites, termos, confins. Em síntese: o levantamento de muros entre um território e outro. Essa separação representada pelo nomos pode ser tanto física quanto simbólica e/ou jurídica (lei, nomos).

Segundo Hannah Arendt (2006, p. 444), na polis grega, a lei nomos - era concebida como um "muro", fronteira que delimitava o espaço em que os cidadãos estavam abrigados e podiam vivenciar a política. A lei instituía um "espaço" entre os homens, pois concedia a eles um "estatuto jurídico" que os habilitava a fazer parte de um espaço público ou comum na qualidade de cidadãos. Esse espaço era regido pela igualdade derivada não de uma "natureza humana", mas de uma convenção artificial, ou seja, um predicado "do mundo feito pelos homens" (ARENDT, 2011, p. 59).

Deste modo, surge o que Schmitt (2006) denomina de antagonismo fundamental da política: a distinção entre o amigo e o inimigo, que dá aos atos e aos motivos humanos sentido político, antecedente ao antagonismo moral (bem e mal), o antagonismo estético (belo e feio) e o antagonismo econômico (útil e danoso). Nesse rumo, o inimigo (hostis) não precisa ser feio ou mal; pelo contrário, ele pode ser belo e moralmente bom, mas seguirá sempre sendo outro, um estrangeiro com o qual cabem, em caso extremo, conflitos existenciais.

Nas palavras de Kristeva (1994, p. 14), "com a construção dos Estados nação [...] estrangeiro é aquele que não tem a mesma nacionalidade", portanto, o "outro" que vem de fora e não pertence à comunidade. Guarda relação com "estranho", designação que só faz sentido dentro de um quadro relacional: o estranho, afinal, só o é em 
comparação a alguém que é familiar. $O$ estrangeiro carrega consigo a marca da estranheza, que o torna diferente daqueles que são familiares. No mesmo sentido, Arnaiz (1998) assevera que a condição de "estrangeiro", por si só, traduz a ideia de uma pessoa que está ocupando ou usurpando um posto ou lugar que não lhe corresponde. 0 Arnaiz (1998, p. 121) destaca que,

en términos filosóficos, puede decirse con razón que la figura del extranjero es uno de los referentes de lo extraño $o$, si se quiere, de la radical extrañeza manifestada em la falta de un suelo (territorio) desde el que identifícarse y en la dificultad de una lengua en la que decirse y ser reconocido. Así, no es de extrañar la generación de toda una gama de sentimientos y posturas que van desde el rechazo pasando por el distanciamiento hasta, talvez, llegar en el mejor de los casos a la compasión.

Embora essa atividade de delimitação e de confinamento caracterize a civilização humana desde os tempos mais remotos, o dispositivo imunitário posto em funcionamento pela Modernidade tem uma potência distinta, de acordo com Esposito (2013). A soberania estatal e o direito individual, juntamente com todas as categorias políticas da Modernidade, de Hobbes a Locke, representam um passo nítido entre o "comum" e o "próprio", gênese da imunização e prevenção do risco comum, no qual convergem a ideia de direito natural e a de contrato social. Frente à ausência de fronteiras da comunidade original, o indivíduo e o Estado nascem sob o signo da separação e da autonomia no interior dos próprios confins, cobrindo o mundo de fronteiras impermeáveis, separando os Estados e, dentro deles, os indivíduos que os habitam.

Somente essa cesura poderia garantir a segurança ausente na comunidade originária, mas o faz cobrando um alto preço ao gerar, segundo Foucault (2000), um nexo estrutural entre a constituição da subjetividade e a sujeição: no mundo moderno, nos tornamos sujeitos somente sujeitando-nos a algo que, por sua vez, nos torna objetos. Somos objetos/cidadãos do Estado, um custo que, segundo Esposito 
(2013), torna-se, contraditório: ativado para afrontar a ameaça da comunidade originária, o paradigma imunitário não faz desaparecer a violência da communitas, mas se incorpora ao dispositivo que deveria abolir. O poder soberano desempenha seu papel de conservação da vida mantendo-a sempre à margem da morte. Em comparação à comunidade original sem lei, a sociedade moderna está salva do risco imediato de extinção. No entanto, ela está exposta a uma violência potencial ainda mais notável, na medida em que é interna a seu próprio mecanismo de proteção. Nesse sentido, a imunização é uma analogia utilizada por Esposito (2010, p. 167) para explicitar que

así como para defenderse preventivamente del contagio se inyecta una porción de mal en el cuerpo que se quiere salvaguardar, también en la inmunización social la vida es custodiada en uma forma que le niega su sentido más intensamente común.

Em um contexto tal, pelo menos potencialmente, a vida humana é convertida em um terreno de decisões que dizem respeito não somente aos seus umbrais externos (como o que distingue a vida animal da vida vegetal), mas também a partir de seus umbrais internos, o que significa dizer que

será concedido o, más bien, exigido a la política el decidir cuál es la vida biologicamente mejor y también como potenciarla a través del uso, la explotación, o si hiciera la muerte de la vida menos valiosa biologicamente. (ESPOSITO, 2006, p. 11).

A partir da teoria de Esposito, fronteiras - immunitas - são estabelecidas em contraponto à violência - communitas, originando o Estado-nação e a filosofia política da Modernidade. Entre seus frutos estão as Declarações de Direitos do século XVIII e a cidadania, realizadoras do objetivo imunizatório máximo, inscrevendo e legitimando a proteção jurídica dos amigos, dos nacionais, nos instrumentos legais e na construção do que seriam os direitos humanos. A cidadania se subordinou à nacionalidade e os direitos garantidos por ela, foram destinados aos nacionais, excluindo-se os "inimigos", ou seja, os de fora, os que pertencem à indiferenciação da communitas. 
A vida nua (a criatura humana) que, no Antigo Regime, pertencia a Deus e que, no mundo clássico, era classificada como zoé e distinguiase da vida política (bios), passa agora ao controle do Estado e se torna o seu fundamento terreno. "Estado-nação significa: Estado que faz da natividade, do nascimento (isto é, da vida nua humana) o fundamento da própria soberania". Nos primeiros três artigos da Declaração de 1789 foi inscrito o elemento nativo no coração de toda associação política, possibilitando a união do princípio da soberania à nação: "conforme ao étimo, natio significa, na origem, simplesmente nascimento" (AGAMBEN, 2015, p. 28).

Constitui-se, assim, a primeira etapa da immunitas moderna, voltada à garantia da ordem frente ao caos da comunidade originária. No entanto, sua função e intensidade começam a mudar a partir da virada biopolítica (FOUCAULT, 2000), quando a política toma como objeto das próprias dinâmicas a vida biológica, a vida humana: os corpos dos indivíduos e das populações, devidamente inscritos nos textos das Declarações, é que passam a estar em jogo nos conflitos políticos decisivos. Uma vez encarnado nos dispositivos excludentes do nacionalismo, o paradigma imunitário, nascido para proteger a vida da comunidade, passa a destruir o que deveria preservar. O marco catastrófico desta inversão, segundo Espósito (2010), está no nazismo, ao conceber como valor absoluto a ser defendido a vida de um único povo, o que justificaria inclusive o sacrifício de qualquer outro povo, ou raça, que a contaminasse de seu interior.

Nascido para limitar a violência da comunidade originária, de acordo com Esposito (2013, p. 26), o paradigma imunitário termina por produzir uma violência muito superior. As fronteiras, instituídas para circunscrever o território soberano dos Estados e proteger o corpo individual de cada cidadão, se fixam em determinado momento "no interior da própria vida humana, como umbrais excludentes, para separar uma parte da vida que se declara superior de outra considerada inferior". Tão inferior a ponto de não ser digna de ser vivida. Os cinquenta milhões de mortos com os quais se conclui a Segunda Guerra Mundial testemunham o ápice catastrófico desse processo. 
Entre a atitude terapêutica e a tanatopolítica, portanto, não há apenas contradição, mas também conexão/complementação. As mortes em massa, no regime nazista, decorreram diretamente da preocupação obsessiva com a saúde do povo alemão. Segundo Esposito (2010, p. 166-167), os médicos nazistas identificavam como "doente" o povo alemão no seu conjunto e "era precisamente a sua cura que requeria a morte de todos aqueles que pela sua simples existência lhe ameaçavam a saúde."

O paradigma imunitário proposto por Esposito (2010, p. 166-167) é, segundo ele, o que melhor se presta a explicar o que levou o nazismo a inverter a proporção entre e vida e morte a favor da segunda até o extremo da autodestruição. Para o autor, o que os nazistas queriam evitar era uma "doença infecciosa" representada pelo "contágio de seres superiores por seres inferiores", ou seja, "a luta contra os judeus era propagandeada pelo regime como sendo a que opunha o corpo e o sangue originariamente saudáveis da nação alemã aos germes invasores que se tinham infiltrado no seu interior com o intuito de minar a sua unidade e mesmo a sua vida." Em virtude disso, o termo mais adequado para designar a biopolítica nazista é o temo zoopolítica, dado que os judeus passaram a ser tratados enquanto animais, meros parasitas que deveriam ser exterminados.

\section{Os paradoxos da cidadania moderna e a proposta de emergência de um novo paradigma histórico em Hannah Arendt}

O projeto de destruição implementado pelo nazismo e seus campos de concentração é justamente o ponto de partida das principais análises de Hannah Arendt. Sob tal marco, a autora (2006) refaz o percurso histórico e teórico da constituição de um vínculo inexorável entre os direitos do homem e o Estado-nação. Seu alerta é que, tomado em sentido contrário, uma vez que a cidadania e a "proteção" representada pela construção histórica dos direitos do homem estejam 
restritas à immunitas das fronteiras do Estado-nação, o declínio de um representaria o declínio de outro.

Nesse marco, a concepção inicial da Declaração dos Direitos do Homem, que os definia como inalienáveis e independentes de governos, acabou sendo desvirtuada. De acordo com a crítica de Arendt (2013, p. 397): "no momento em que seres humanos deixavam de ter um governo próprio, não restava nenhuma autoridade para protegê-los e nenhuma instituição disposta a garanti-los". É assim que Arendt (2013, p. 399) explica a vulnerabilidade das pessoas desprovidas de ligação política com um Estado-nação: "os Direitos do Homem, supostamente inalienáveis, mostraram-se inexequíveis - mesmo nos países cujas constituições se baseavam neles - sempre que surgiam pessoas que não eram cidadãos de algum Estado soberano".

Esta é, segundo Giorgio Agamben (2015), uma formulação que precisa ser levada a sério, uma vez que, ao vincularmos indissoluvelmente os destinos do direito do homem ao destino do Estado nacional moderno, o declínio de um implicará, necessariamente, o devir obsoleto do outro. Nesse marco, o fato de alguns indivíduos apresentaremse absolutamente desprovidos de direitos apresenta-se vinculado à circunstância de que eles já não pertencem a qualquer comunidade, sua situação "não resulta do fato de não serem iguais perante a lei, mas sim de não existirem mais leis para eles; não de serem oprimidos, mas de não haver ninguém mais que se interesse por eles, nem que seja para oprimi-los" (ARENDT, 2013, p. 402).

A convergência denunciada pela autora baseava-se no pressuposto implícito de que o padrão de normalidade era a divisão, em escala mundial, dos seres humanos em Estados nacionais, segundo o paradigma imunizatório (ESPOSITO, 2010). Na perspectiva de Arendt, em sentido oposto, a crise dos direitos humanos está diretamente relacionada à crise do Estado, na medida em que este, sedimentado na cidadania nacional, deixou de alcançar as pessoas desprovidas de nacionalidade. Foi justamente a emergência histórica dos displaced people, refugiados, apátridas e todos os demais "expulsos da trindade Povo-Estado-Território” (LAFER, 1997, p. 58), a partir da Primeira Guerra 
Mundial, que assinalou, em Arendt, o ponto de ruptura cujo cerne foi a dissociação entre os direitos humanos e os direitos dos povos e a emergência de um novo paradigma histórico a partir de então.

No mesmo sentido, observa Guimarães (2013, p. 26-27), a problemática de um sistema de Estados-nação na Europa reside no "aparecimento" de um conjunto de minorias que não eram passíveis de "acomodação" nessa lógica. Uma vez configurada a inseparabilidade dos direitos humanos da soberania estatal, "as dezenas de milhões de pessoas sem nação na Europa eram também, em princípio, semdireitos, porque o princípio do Estado-nação os deixara sem um garante político efectivo dos seus direitos".

A partir de tal fenômeno histórico, Hannah Arendt conclui que a cidadania é o direito a ter direitos, pois a igualdade em dignidade e direito dos seres humanos não é um dado, mas um construído da convivência coletiva, que requer o acesso a um espaço público comum. A igualdade

não nos é dada, mas resulta da organização humana, porquanto é orientada pelo princípio da justiça. Não nascemos iguais: tornamo-nos iguais como membros de um grupo por força da nossa decisão de nos garantirmos direitos reciprocamente iguais (ARENDT, 2006, p. 335).

É, portanto, o acesso ao espaço público, o direito de pertencer a uma comunidade política, que permite ao cidadão assegurar seus direitos de humanidade, e a perda desse "lugar no mundo" é também o que o expulsa da humanidade, a despeito da proteção abstrata e universalista dos direitos humanos:

O grande perigo que advém de pessoas forçadas a viver fora do mundo comum é que são devolvidas, em plena civilização, à sua elementaridade natural, à sua mera diferenciação. Falta-lhes aquela tremenda equalização de diferenças que advém do fato de serem cidadãos de alguma comunidade, e no entanto, como já não se thes permite participar do artifício humano, passam a pertencer à raça humana da mesma forma como os animais pertencem a uma dada espécie de animais (ARENDT, 2006, p. 335). 
A negação do direito à cidadania colocou os homens em sua condição natural, em estado de natureza; e, como tal, apenas vidas "descartáveis". A humanidade, "concebida durante tanto tempo à imagem de uma família de nações, havia alcançado o estágio em que a pessoa expulsa de uma dessas comunidades rigidamente organizadas e fechadas, via-se expulsa de toda família de nações". Não havia mais nenhum país no qual pudessem ser assimilados, nenhum lugar onde pudessem formar uma nova comunidade e, não por falta de espaço, mas por falta de vontade política (ARENDT, 2006, p. 327). De fato, corrobora Lafer (1997, p. 46), "à medida que os refugiados e apátridas se viram destituídos, com a perda da cidadania, dos benefícios do princípio da legalidade, não puderam se valer dos direitos humanos, não encontrando lugar no mundo do século XX", inteiramente organizado e ocupado politicamente a partir das fronteiras estatais. Agamben (2015, p. 27), revisitando Arendt, sustenta que houve a criação de um paradoxo em torno da figura do refugiado, pois aquele que deveria "encarnar por excelência os direitos do homem assinala, ao contrário, a crise radical desse conceito".

Arendt percebe que, a despeito da longa trajetória, as evocações solenes dos direitos inalienáveis do homem demonstraram-se absolutamente incapazes não só de resolver o problema, mas simplesmente de enfrentá-lo, conforme Agamben (2015). Impotência que residiria não só no egoísmo e na cegueira dos aparatos burocráticos, mas na ambiguidade das noções fundamentais que regulam a inscrição do nativo (da vida) no ordenamento jurídico do Estado, plenamente evidenciada, segundo o filósofo italiano, no paradoxo representado pelo refugiado, e já implícito na própria ambiguidade do título da declaração de 1789, Declaração dos Direitos do Homem e do Cidadão, no qual não está claro se os dois termos "nomeiam duas realidades distintas ou se fornecem, ao contrário, uma hendíadis, na qual o primeiro termo já está, na verdade, sempre contido no segundo" (AGAMBEN, 2015, p. 27).

De acordo com Agamben (2015, p. 27), "no sistema do Estadonação, os assim chamados direitos sagrados e inalienáveis do homem mostram-se desprovidos de qualquer tutela no próprio momento em que 
não é mais possível configurá-los como direitos dos cidadãos de um Estado". Logo, de acordo com a análise de Arendt (2013, p. 408),

o conceito de direitos humanos, baseado na suposta existência de um ser humano em si, desmoronou no mesmo instante em que aqueles que diziam acreditar nele se confrontaram pela primeira vez com seres que haviam realmente perdido todas as outras qualidades e relações específicas - exceto que ainda eram humanos. $O$ mundo não viu nada de sagrado na abstrata nudez de ser unicamente humano.

Como observa Giacoia Junior (2008, p. 294), "ao lado da função emancipatória das declarações de direitos fundamentais, seria também indispensável perceber que elas integram o dispositivo de abandono da vida nua à violência dos mecanismos de poder". Com efeito, sem a fronteira estatal e sua nacionalidade, o que restava era uma condição de completa privação de direitos antes mesmo que o direito à vida fosse ameaçado. A ausência de lei para os "sem lugar" deu-se inicialmente pela privação total dos direitos, depois pela ameaça à vida e, por fim, o internamento no campo (ARENDT, 2006, p. 321). Essa sequência foi observada rigidamente pelo estado nazista que, mesmo ao longo de sua "solução final", garantia a completa desnacionalização de judeus e ciganos antes de seu envio aos campos. Quando seus direitos não são mais direitos do cidadão, "então o homem é realmente sagrado, no sentido que esse termo tem no direito romano arcaico: voltado à morte" (AGAMBEN, 2015, p. 30).

Os sem cidadania, apesar de muitos, não eram perseguidos por algo que tivessem feito ou pensado, "e sim em virtude daquilo que imutavelmente eram - nascidos na raça errada, ou na classe errada" (ARENDT, 2006, p. 328), elevando a fronteira nacional (física ou simbólica) a elemento responsável pela condição de humanidade ou inumanidade de um ser. A partir dessa experiência de redução da humanidade, jurídica e faticamente, à condição de descarte, contrariando, segundo Celso Lafer (1997), frontalmente os valores formalmente consagrados no Direito, é que Arendt identifica o que deveria ser uma profunda 
ruptura na filosofia política tida até então, e, a partir daí, a emergência de um novo paradigma histórico.

Desse fenômeno resultou o esfacelamento dos padrões e categorias que constituíram o conjunto da tradição ocidental, que havia historicamente feito da pessoa humana (o amigo) um valor-fonte da experiência ético jurídica. Consequentemente, disso adveio também um "hiato entre o passado e o futuro", uma vez que a tradição, segundo Lafer (1997, p. 56), inclusive a jurídica, passa a não nos oferecer "critérios para a ação futura, nem conceitos para o entendimento dos acontecimentos passados". Fica claro, a partir da elaboração de Hannah Arendt, que "um estatuto estável do homem em si mesmo é inconcebível no direito do Estado-nação", corrobora Agamben (2015, p. 28).

A construção de um mundo comum, baseado no direito de todo ser humano à hospitalidade universal apontada por Kant e contestada na prática pelos refugiados, só começaria a se tornar viável, como aponta Hannah Arendt (2006), se o direito a ter direitos fosse universalmente tutelado a partir do ponto de vista da humanidade. Para tanto, a autora busca na moral universalista e cosmopolita kantiana o conceito de humanidade, atribuindo-o à dimensão política necessária para se compreender o espaço público internacional, em que o direito a ter direitos decorra do mero pertencimento a ela, não se dissolvendo nos limites de cada nação. Está aí o grande chamado que Hannah Arendt deixou ao mundo após 1950: resgatar a humanidade perdida nos confins do Estado-nação.

\subsection{O mundo após Hannah Arendt: o avanço das fronteiras imunizatórias nos marcos da biopolítica}

Passados mais de 70 anos do fenômeno original dos campos de concentração e da formulação arendtiana, será que levamos a sério a tarefa de desvincular a cidadania e a proteção da humanidade das fronteiras do Estado-nação? Que lugar ocupam os refugiados, imigrantes e apátridas na sociedade política do século XXI? 
A doutrina dos direitos humanos efusivamente tem reiterado que, a partir da "ruptura" evidenciada por Arendt, o mundo inaugurou a chamada concepção contemporânea dos direitos humanos, introduzida com a Declaração Universal de Direitos Humanos de 1948, conforme aduz Flavia Piovesan (1997). Tal concepção estaria vinculada ao processo de internacionalização e universalização e o consequente desenvolvimento do Direito Internacional dos Direitos Humanos, segundo Cançado Trindade (2002), que representaria a criação de uma sistemática internacional de proteção capaz de permitir a responsabilização do Estado. Permitiria, portanto, conforme Piovesan (1997), a revisão da noção tradicional de soberania do Estado, e a cristalização da ideia de que o indivíduo deve ter direitos protegidos na esfera internacional.

Teve início a partir de então a progressiva construção de um arcabouço internacional formado por um conjunto de declarações, pactos, convenções e órgãos especializados da Organização das Nações Unidas (ONU) e, inclusive, Cortes Internacionais, em um movimento crescente sem precedentes na história. Segundo Celso Lafer (1999), as consequências e a atualidade da conclusão arendtiana foram reconhecidas pelo Direito Internacional Público contemporâneo, o qual passou a considerar a nacionalidade como um direito humano fundamental, além de buscar substituir as insuficiências do mecanismo de proteção diplomática pelas garantias coletivas, confiadas a todos os Estados-parte nas Convenções Internacionais dos Direitos Humanos.

Todo este aparato jurídico-político impressiona pela grandiosidade e pretensões sob as quais se apresenta. Seu teste de validade, no entanto, sob a perspectiva arendtiana pode ser feito a partir de seu confronto com o refugiado ${ }^{1}$, aquele tido por Hannah Arendt como o

\footnotetext{
Para fins deste estudo não serão estabelecidas diferenciações formais entre refugiados, imigrantes, migrantes, apátridas, asilados, uma vez que, a despeito da definição formal atribuída pelas legislações internacionais e pelas burocracias estatais, tratam-se de pessoas que se encontram fora das fronteiras estatais, sejam elas físicas, simbólicas ou culturais, e portanto, desabrigadas da proteção formal da cidadania e do acesso aos direitos humanos globalmente consagrados. Para tanto, utilizaremos a expressão refugiados e um modo amplo, a abarcar todos aqueles que se encontram em tal condição.
} 
grande precursor de um novo paradigma da filosofia política, aquele que, caçado de país em país representava, segundo a autora, a vanguarda de seu povo: qual é a condição jurídico-política do refugiado na geopolítica contemporânea? Há, para ele, proteção sob o longo braço do Direito Internacional dos Direitos Humanos? Ou, ao contrário, sua condição de humanidade vem ruindo tão ou mais depressa que sua relação com o Estado que lhe deveria conceder reconhecimento e proteção? Em suma, a construção do Direito Internacional dos Direitos Humanos levou a sério a formulação de Hannah Arendt?

Obviamente, um olhar atento aos fatos que marcam o cenário internacional em meados desta segunda década do século XXI nos leva a afirmar que não. Não só não aprendemos a lição de Hannah Arendt, como o fenômeno dos campos, ao contrário de impor um limite, aprofundou o processo tanatopolítico da immunitas, iniciado com o estabelecimento das fronteiras, aprofundando a cesura entre a vida que merece ser vivida e a vida descartável.

A derrota do nazismo, ao contrário de debilitar os dispositivos imunitários, os potencializou ainda mais, e o processo de imunização se estendeu por todas as partes. O nó entre política e vida, segundo Esposito (2013), cuja variação tanatopolítica deu lugar ao nazismo, aparece hoje mais forte que no passado, embora enormemente alterado em suas modalidades e em seus fins. A demanda por segurança se converteu numa síndrome obsessiva, invertendo a relação normal entre perigo e proteção. Já não é a presença do perigo que cria a demanda por proteção, mas a demanda por proteção o que gera artificialmente a sensação de perigo, segundo o filósofo italiano.

Naturalmente, o fenômeno da globalização em muito influenciou o aumento do paradigma imunizatório no mundo contemporâneo. A globalização e suas consequências catastróficas ${ }^{2}$ tornaram-se, a partir

\footnotetext{
2 Denominação que, segundo Judith Butler (2009, p. 24), nada mais é do que um "eufemismo medíocre e enganoso para o que se poderia chamar de mundialização da lei estatal do valor do capital".
} 
de sua afinidade estrutural e simbólica com a comunidade originária, o mito de um mundo caótico e ingovernável, inferno, selva, estado de natureza, um paradigma a ser combatido. Ambas são ilimitadas, fluidas e invertebradas, destinadas a empurrar o mundo a uma mobilização constante que transgride fronteiras por meio de migrações, embora, ao mesmo tempo, fluxos de informações e de capital circulem livremente em tempo real. "Se a Hobbes, Locke e Vico Ihes parecia que a comunidade originária não tinha freio algum [...], nada parece hoje mais desenfreado que o processo de globalização" (ESPOSITO, 2013, p. 27).

Naturalmente, não há que se confundir realidade e imagem difundida, uma vez que, segundo Esposito (2013, p. 27), "no modelo atual de globalização, o mundo se unificou por sua própria divisão: está ao mesmo tempo mais unido e mais dividido como nunca estivera". $\grave{A}$ medida que seu efeito principal é gerar comunicação, a globalização promove uma contaminação infinita entre homens, povos e linguagens, até o ponto de não haver espaço para qualquer diferença. É contra este contágio que opera o dispositivo imunitário, naquilo que Esposito (2013, p. 28) denomina de rechaço: "quanto mais contato têm entre si grupos étnicos, religiosos ou linguísticos, invadindo os espaços recíprocos, maior é o impulso oposto que conduz a um novo localismo, uma nova obstinação identitária" que, por sua vez, conduz à maior epidemia de construção de muros da história humana. Junto com os muros, são traçadas novas linhas de bloqueio, novas redes de 'proteção' capazes de deter, ou retardar a invasão dos outros, a confusão entre dentro e fora, interior e exterior, nós e eles.

O efeito potencialmente catastrófico dessa perversa estrutura entre o global e o local é visível nos acontecimentos recentes que demonstram que o excesso de imunidade produz mais violência do que é capaz de evitar. Os direitos universais figuraram em proclamações privadas de realidade e o direito à vida é traído e desmentido a cada dia por milhões de mortos de fome, enfermidades e guerras (ESPOSITO, 2010). Quanto mais "frutos envenenados produz a globalização, mais parecem fechar-se as fronteiras para aqueles que buscam amparo e 
subsistência fora de seus países de origem", ou seja, para os refugiados, aos quais já se referia Hannah Arendt ${ }^{3}$.

Cabe questionar então, como esta situação pode ser explicada à luz da proliferação tida como vitoriosa do Direito Internacional dos Direitos Humanos? Agamben (2015) reflete sobre esta aparente contradição evidenciando que, no pós-guerra, a ênfase instrumental nos direitos do homem e o multiplicar-se de Declarações e Convenções no âmbito das Organizações Supranacionais acabaram por "impedir uma compreensão autêntica do significado histórico do fenômeno". No entanto, para o autor (2015), é hora de deixar de ver as Declarações como proclamações gratuitas de valores eternos metajurídicos, que vinculam a princípios éticos eternos, para considerá-las a partir de quais sejam suas reais funções históricas na formação do moderno Estadonação. Elas representam, para o autor, a figura original da inscrição da vida natural no ordenamento jurídico-político do Estado-nação. Vida que entra agora, a partir da biopolítica, em primeiro plano na estrutura do Estado e até se converte no fundamento de sua legitimidade e soberania.

É à luz dessa compreensão proposta por Agamben (2015) que se pode retomar a análise do refugiado, enquanto figura capaz de romper a continuidade entre homem e cidadão, nascimento e nacionalidade, destruindo a ficção originária da cidadania moderna. Por um momento, o refugiado faz com que apareça na cena política aquela vida nua que constitui sua premissa secreta, representando, como já bem afirmou Hannah Arendt, a primeira e única aparição real do homem, sem a máscara de cidadão que constantemente o encobre. Por representar a própria subversão à ordem é que a sua figura resta tão difícil de definir

3 De acordo com o Relatório Viagens Letais, produzido pela Organização Internacional de Migrações (OIM) e considerado o mais abrangente estudo global sobre mortes de imigrantes na terra e no mar, somente em 2014, quatro mil imigrantes perderam suas vidas no trajeto para escapar da violência e da pobreza dos países de origem. Destes, mais de três mil perderam as vidas ao cruzar o Mediterrâneo para chegar ao continente europeu e outros 230 morreram na fronteira entre México e Estados Unidos. Essa média vem se mantendo há pelo menos 14 anos. Embora sejam estimativas alarmantes, o documento da OIM acredita que o número deva ser superior, pois não são todas as mortes que são registradas. Segundo analistas, para cada corpo de imigrante encontrado, há dois que permanecem desaparecidos. Disponível em:<http:// operamundi.uol.com.br/>. Acesso em: 30 jul. 2015. 
em termos modernos, como afirma Bourdieu (1998, p. 11): "nem cidadão nem estrangeiro, nem totalmente do lado do Mesmo, nem totalmente do lado do Outro, o "imigrante" situa-se nesse lugar "bastardo" [...] a fronteira entre o ser e o não-ser social". Deslocado, suscita o embaraço, refletido na dificuldade que se experimenta em pensá-lo a partir dos pressupostos e omissões da visão oficial.

O imigrante/refugiado constitui-se em um conceito-limite que expõe a crise radical dos princípios do Estado-nação e, ao mesmo tempo, permite liberar o campo para uma renovação categorial necessária. Considerado ilegal na maioria dos países, esse contingente está assumindo proporções cada vez maiores e exige uma mudança de postura dos Estados, que tem diante de si uma "massa estavelmente residente de não-cidadãos" (BOURDIEU, 1998), que não podem nem querem ser naturalizados nem repatriados. Esses não-cidadãos têm frequentemente uma nacionalidade de origem, mas enquanto preferem não usufruir da proteção de seu Estado, encontram-se na condição de "apátridas de fato". Paralelamente, sua presença, e a assimilação substancial das diferenças que representam, exaspera o ódio e a intolerância, e faz crescer as reações xenofóbicas e as mobilizações defensivas da immunitas.

Como destaca Ferreira (2011, p. 264), os imigrantes, pela sua própria existência - e não necessariamente por meio de manifestações políticas conscientes - acabam por subverter o lugar comum (topoi) e obrigam a coletividade "a questionar a validade de conceitos e identidades estanques, fixas, imutáveis (conceitos e identidades emuralhadas)." Isso porque os migrantes "promovem o pensamento e a prática do kosmopolites, fazendo com que a Soberania territorial, dogmática e exclusiva, seja contestada."

A par de tudo isso, convém refletir sobre o sentido da análise de Hannah Arendt que hoje, mais de setenta anos depois, ainda se mostra atual. Não só o problema se apresenta no mundo com idêntica urgência, mas, no declínio agora irrefreável do Estado-nação e na corrosão geral das categorias jurídico-políticas tradicionais, o refugiado é, segundo Agamben (2015, p. 24), talvez “a única figura pensável do povo no 
nosso tempo e, ao menos até quando não for realizado o processo de dissolução do Estado-nação e da sua soberania, a única categoria na qual é hoje permitido entrever as formas e os limites de uma comunidade política por vir". E se quisermos, como aduz Agamben (2015, p. 24), "estar a altura das tarefas absolutamente novas que estão diante de nós", devemos levar a sério as teses de Hannah Arendt que vinculavam o destino dos direitos ao Estado, de modo que o ocaso deste não suponha o fim daquele. Para tanto, devemos estar dispostos a desconstruir os conceitos fundamentais com os quais temos aprisionado a humanidade às fronteiras, sejam elas físicas, simbólicas ou culturais, do mundo dos Estados-nação.

\section{Um Estado, várias nações unidas pela humanidade: a proposta de Judith Butler}

Levar a sério a proposição de Hannah Arendt e o aviso dado por Agamben e reformular as categorias básicas da filosofia política moderna parece ser uma tentativa constante na teoria da filósofa americana Judith Butler (1998). A autora, em uma entrevista concedida ao jornal Folha de São Paulo, em 20 de setembro de 2015, durante sua recente visita ao Brasil, ao analisar o cenário mundial atual afirmou:

em dado momento, todos teremos de saber que pertencemos uns aos outros e que há formas de pertencimento com claras implicações éticas e políticas que transcendem o Estado-nação. [...] Se perguntarmos porque devemos nos preocupar com refugiados em busca de abrigo e segurança em outro canto do mundo, talvez sejamos obrigados a questionar o que nos une a outras pessoas, inclusive as que não conhecemos e não conheceremos. [...] Acredito que estejamos unidos aos que não conhecemos e não conheceremos, e eles a nós sem saber nossos nomes. Esta ligação anônima é crucial para a ideia de responsabilidade global $^{4}$ (BUTLER, 2015).

Inteiro teor disponível em: <http://www1.folha.uol.com.br/ilustrissima/2015/09/1683172-semmedo-de-fazer-genero-entrevista-com-a-filosofa-americana-judith-butler.shtml>. Acesso em: 18 nov. 2015. 
Os estudos de Judith Butler (1998) partem de questões de gênero, a partir das quais ela propõe a desconstrução das configurações de identidade, deslocando o pensamento do binarismo homem/mulher e voltando sua atenção para a inclusão dos indivíduos inadequados ao ideal normativo dominante. Sua proposta é, portanto, a desconstrução da identidade de gênero a partir da constatação de que não há uma essência ou substância que o defina. Na verdade, "o gênero não deve ser meramente concebido como a inscrição cultural de significado num sexo previamente dado", defende Butler (1998, p. 40), mas "tem de designar também o aparato mesmo de produção mediante o qual os próprios sexos são estabelecidos." Este aparato se constitui pela repetição de atos, gestos e signos, do âmbito cultural, que reforçariam a construção dos corpos, tratando-se, portanto, de uma questão de performatividade.

Butler analisa grupos como transsexuais, intersexos, homossexuais e transgêneros, abordando o problema da sua (in)adequação a um ideal normativo, que os torna "patológicos". Reflete, a partir de então, sobre a definição do que é humano e de como se dá seu reconhecimento. Para Butler (1998, p. 36), a tentativa de estipular conceitos universais a partir de identidades pré-definidas soa excludente e contraditória: "as categorias de identidade nunca são meramente descritivas, mas sempre normativas e, como tal, exclusivistas". Desse modo, a tentativa tradicional de constituir a identidade dos sujeitos a partir da descrição revela-se um ato de normatização, controlando, pela exclusão e prédefinição, comportamentos linguísticos e sociais em geral. $O$ perigo na definição de critérios a priori de humanidade está no seu oposto, ou seja, na produção do menos "humano", do inumano, do abjeto, justamente aqueles a quem a autora (2010) quer dar conta, concedendo humanidade ao inabitável, ao "invivível", ao Outro que virou "merda".

Falando de corpos que importam, e ao contrário, dos que não importam, considerados abjetos pela norma, desconstituídos de humanidade e invisíveis, seu engajamento começa a ultrapassar o enquadramento filosófico feminista. Volta-se, desse modo, à tentativa ética de desvincular do caráter patológico aqueles que apresentam complexidades não absorvidas pelo ideal normativo para, a partir da 
desmistificação das configurações sociais excludentes, devolver-lhes o direito básico a uma existência legítima (BUTLER, 1993). Segundo Butler (2002, p. 162), "o abjeto para mim não se restringe de modo algum a sexo e heteronormatividade. Relaciona-se a todo tipo de corpos cujas vidas não são consideradas 'vidas' e cuja materialidade é entendida como não importante".

A produção da vida abjeta, ou seja, da vida que não merece ser lamentada, passa a ser analisada a partir de situações como a guerra no Iraque e o campo de Guantánamo (BUTLER, 2009). Ao refletir sobre a diferença de tratamento dispensado às mortes provocadas pelos atentados terroristas nos EUA e as mortes perpetradas pelos EUA na luta contra o terrorismo, a autora busca discutir o que conta como humano, ou seja, as vidas que efetivamente contam como vidas e, ao contrário, aquelas que não valem a pena, que não merecem ser lamentadas. Há, como denuncia Butler (2009), uma nítida separação, uma fronteira simbólica entre ambas, de modo que um atentado contra a santidade de uma bastaria para mobilizar a guerra, e de outra seria mero efeito colateral. A produção desta separação é determinada ainda pelas fronteiras estatais, embora agora, com Butler, estejamos falando também das fronteiras simbólicas e culturais que estabelecem cesuras entre as várias nações existentes no Estado.

Esta "desrealização do outro" o torna um ser nem vivo nem morto, mas em uma interminável condição de "espectro", determinada pela alteridade, ou seja, pela nossa capacidade de nos importarmos, ou não, com a humanidade do outro. O que nos vincula eticamente à alteridade, ao outro, compreendido como as pessoas marcadas por vidas precárias, é um questionamento que a autora busca responder. Para Butler (2011, p. 27), este vínculo "não é um a priori, antes emerge apenas quando reconhecemos a humanidade deste Outro sob ameaça". Infelizmente, em tempos globalizados, quando a comunicação massiva e distorcida, ao contrário de nos aproximar, gera a "contaminação" à qual se refere Esposito (2010). Com isso, aumentam os dispositivos imunizadores e, consequentemente, o mundo encontra grandes dificuldades em reconhecer a alteridade do outro e produzir a sua identificação com ela. 
A representação da alteridade constitui-se em um meio de humanizar e des-humanizar, de reconhecer o vínculo ético-moral com o outro ou de justificar sua eliminação (BUTLER, 2011). Este esvaziamento do humano questiona os esquemas normativos capazes de estabelecer o que será uma vida habitável ou uma morte a ser lamentada. Tais esquemas produzem ideais de humanidade e do que seja o "menos humano", e também "funcionam sem fornecer nenhuma imagem, nenhum nome, nenhuma narrativa, de forma a concluir que ali nunca houve morte tampouco vida" (BUTLER, 2011, p. 28). Produz-se, assim, uma identificação simbólica do rosto com o inumano, ou um apagamento radical da própria humanidade, tornando "o desfazer da percepção de perda, a insensibilidade à dor e ao sofrimento como mecanismo por meio do qual a desumanização se consuma" (BUTLER, 2011, p. 28-29).

No livro intitulado “¿Quién le canta ao Estado-Nación?” (2009), no qual dialoga com Gayatri Spivak, Butler parte do momento atual de crise do Estado-nação e reflete sobre a possibilidade de um pertencimento ao Estado cujas bases não sejam nacionais. Tomando como referência os questionamentos de Hannah Arendt acerca da exclusão dos não nacionais do pertencimento ao Estado, Butler (2009) acredita que a única forma de pensar um novo tipo de pertencimento, capaz de incluir a humanidade descartada, seja abrindo mão do léxico tradicional EstadoNação. A partir daí, deveria partir-se de um novo vocabulário, que se não existe, deve ser criado, para que seja capaz de descrever e desconstruir a privação de direitos advinda do pertencimento excludente às fronteiras estatais.

Diferentemente de Arendt, Butler (2010) não se refere especificamente ao refugiado e ao imigrante enquanto pessoas que foram privadas da cidadania pela expulsão de seu Estado originário. Em termos biopolíticos, e levando em consideração o avanço do processo imunizatório identificado por Esposito, sua análise se refere também àquelas vidas que, mesmo sob a fronteira do Estado-nação e sob o espectro das legislações protetoras de direitos e da cidadania se tornaram descartáveis, matáveis, ou seja, às diversas nações sem Estado que se encontram dentro do Estado-nação. 
Segundo Butler e Spivak (2009, p. 55), a divisão dentro/fora da fronteira física de um estado "es la que ordena la discusión de Arendt [...] tal vez porque su análisis del refugiado está acotado al del exiliado, alguien que ha dejado un lugar y llega a otro". No entanto, a ideia de cruzar um território a outro requer uma linha narrativa entre lugar de partida e lugar de chegada, que constitui "el 'antes' y el 'ahora' tanto como el 'allá' y el 'acá' de una trama, una topología y un desarrollo narrativo". A autora questiona a estabilidade destes lugares de partida e chegada, cujo trajeto não daria conta da complexidade dos deslocamentos atuais. Lugares de chegada e de partida são conceitos que devem ser des/ re-construídos a partir da consideração da saída que ocorre a partir de dentro, "a la desposesión que tiene como condición la inmovilidad. Tal parece ser el caso de alguien que acaba de quedarse, a la vez, confinado y desposeído en el mismo territorio del que sale y entra".

Não basta, nesse caso, considerar a definição de refugiado como a população que se desloca entre estados juridicamente autônomos. Se o Estado é uma estrutura legal que dá proteção aos seus cidadãos, quando se chega a ele sem estar incluído no conjunto de direitos e obrigações jurídicas dessa cidadania, pode-se dizer que se chegou a um Estado? "Precisamente, no como ciudadano; es recibido, bajo la condición de no estar incluido en el conjunto de los derechos y obligaciones jurídicos que definen la ciudadanía". Ainda que exista um lugar de chegada, este não necessariamente será outro Estado que produza modos de inclusão; poderia ser Guantánamo, por exemplo, onde não há Estado. Afinal, embora Estados sejam lugares de poder, esses nem sempre são "o" Estado-nação, existindo, por exemplo, estados não nacionais ou estados de segurança, que destroem constantemente as bases nacionais do Estado. “Así, el término 'estado' puede ser dissociado del término 'nación”' (BUTLER; SPIVAK, 2009, p. 45-47).

O Estado tem o condão de definir a estrutura legal e institucional que serve de matriz para os direitos e obrigações do cidadão, ao estabelecer as condições pelas quais se tornam juridicamente vinculados. Embora seja esperado que o Estado defina modos de pertencimentos jurídicos, pode, ao contrário, negar ou suspender a proteção legal, tornando- 
se fonte do não pertencimento. "Si el estado es lo que vincula [...] en nombre de la nación, conjurando forzosa si es que no poderosamente cierta versión de la nación, entonces también desvincula, suelta, expulsa, destierra" (BUTLER; SPIVAK, 2009, p. 45). O que nem sempre se dá de modo emancipatório, ou seja, "deixando ir" ou "liberando"; mas pressupõe a prisão, através de um poder que imuniza, impondo cesuras, fronteiras, barreiras e prisões.

Desse modo, o Estado supõe uma nação que expresse certa identidade nacional, fundada no consenso coletivo vinculante. Nação que deve ser pretensamente singular e homogênea, produzindo, para tanto, modos de pertencimento nacional classificatórios e excludentes. "El estado deriva su legitimidad de la nación, lo que significa que las minorías nacionales que no califican para 'pertenecer a la nación' son consideradas como habitantes 'ilegítimos". Nesse contexto, "el estatus que confiere la condición de sin-estado a un grupo de personas se vuelve el medio por el cual los sin-estado son producidos discursivamente dentro de un campo de poder, vez que son privados de derechos" (BUTLER; SPIVAK, 2009, p. 65).

A separação, portanto, pode assumir a forma de prisão, fazendo com que as minorias descartadas sejam confinadas no interior do território. Ela também pode se dar mediante a forma clássica de expulsão a um espaço exterior, que pode, ou não, ser outro Estado-nação. 0 que distingue a prisão da expulsão depende de como se consideram os limites entre estar dentro e estar fora, embora ambos sejam mecanismos utilizados para traçar dito limite, física ou simbolicamente. "El límite comienza a existir políticamente desde el momento en que alguien pasa o es privado del derecho de passo" (BUTLER; SPIVAK, 2009, p. 67).

Para analisar o tipo de situação complexa que deriva do processo de imigração internacional na atualidade, baseados tanto na expulsão quanto na exclusão, Butler faz referência ao que chama de episódio do hino, a partir do qual propõe a criação de um novo modelo para pensar o pertencimento ao Estado. Trata-se de um episódio acontecido na primavera de 2006, nas ruas de Los Angeles, na Califórnia, quando 
imigrantes irregulares fizeram uma marcha na qual cantaram o hino nacional americano em espanhol. Chamado de "nuestro himno", o episódio introduziu, segundo Butler e Spivak (2009, p. 83-84), o problema da pluralidade "de la nación, del 'nosotros' y del 'nuestro'. ¿A quién pertenece este himno?", e a quem pertence o Estado? Há um "nós" que canta e que se afirma em espanhol reivindicando um modo de pertencimento à nação. "Un modo de pertenencia, porque ¿quién está incluido en ese 'nosotrós'? El 'nosotros' que canta y que se afirma en español tiene, sin duda, efectos sobre nuestra concepción de la nación y de la igualdad."

O então presidente Bush responde ao ato dizendo que o hino nacional só pode ser cantado em inglês, expressando um requisito monolinguístico da nação. Em termos arendtianos, este seria, "el momento en el que una mayoría nacional trata de definir la nación en sus propios términos, estableciendo o reforzando normas de exclusión que deciden quién puede ejercer la libertad, puesto que dicho ejercicio depende de actos de lenguaje" (BUTLER; SPIVAK, 2009, p. 84). A contrario sensu, se determinado grupo define a nação por seus próprios termos, é também mediante a ação, nos termos arendtianos, que Butler encontra um forte aporte à sua noção de política como performatividade. No exercício de cantar o hino, os imigrantes em situação irregular reivindicam o pertencimento ao Estado pela via da nação. Não se trata de um mero pedido de acesso à nacionalidade, mas uma contradição performativa, cantada na rua, local cujo uso para tal fim é proibido pela lei americana. O ilegal reivindica tornar-se legal, desafiando a mesma lei da qual exige reconhecimento.

É uma contradição porque o direito exercido não existia dejure, e é performativo porque exercido através de enunciados, ou seja, atos de fala. Os imigrantes que dele participam exerciam direitos, embora não os tivessem, reivindicando, através do exercício, o próprio direito a ter direitos. "Fuera de toda legalidad, reclama garantías y protección legal". Com isso, "los derechos tienen una doble existencia, ya que en la calle y en el canto hay un ejercicio del derecho al derecho, y el primero de esos derechos no está garantizado por ninguna ley sino que pertenece a la 
naturaleza de la igualdad en tanto condición social antes que natural". De seu meio, "lo que se escucha son las palabras somos iguales", afirmação da qual brotam inúmeros questionamentos, afinal, "un acto de habla como este, que no solo declara abiertamente la igualdad del 'nosotros', sino que también exige una traducción" não impõe a tarefa de tradução/reconstrução da própria ideia de nação? Seria, portanto, uma reprodução não autorizada da nação, ou expressaria sua falência total? (BUTLER; SPIVAK, 2009, p. 86).

Para essas perguntas não há uma resposta clara, dada sua própria contradição. Porém, na visão de Butler, são exatamente essas contradições que, quando tornadas públicas, permitem reelaborar a linguagem dominante e repensar as formas de distribuição de poder, atitudes necessárias caso se pretenda promover mudanças radicais em uma sociedade. Repensar o (não)pertencimento ao Estado de forma a torná-lo não nacionalista é considerada uma mudança radical, e é nesse sentido que Butler, ainda que não esteja segura de quais serão os efeitos concretos de ditos atos, se posiciona favoravelmente às reivindicações políticas fundamentadas em contradições performativas.

Afinal, "no pude haber una política de cambio radical sin contradicción performativa". Exercer liberdade e afirmar igualdade em uma relação de autoridade que as exclui é mostrar como ambas podem e devem ir além das articulações e conceitos existentes. "La contradicción debe ser tomada en cuenta, expuesta y elaborada para convertirse en algo nuevo" (BUTLER; SPIVAK, 2009, p. 86). Neste sentido, a contradição performativa de Butler, poderia conduzir à profanação, como condição de possibilidade para o rompimento da separação promovida pela sacralização, devolvendo à esfera dos homens aquilo que foi consagrado aos deuses. Afinal de contas, etimologicamente, "puro, profano, livre dos nomes sagrados, é o que é restituído ao uso comum dos homens", de modo que a profanação seria o ato de restituir ao livre uso dos homens o que havia sido separado, interditado, impossibilitado, desativando "os dispositivos do poder e devolvendo ao uso comum os espaços que ele havia confiscado" (AGAMBEN, 2007, p. 65-68). 
Quanto ao hino, afirma Butler (2009, p. 91), o que se coloca "no es si el himno nacional debe ser cantado en español", afinal, as pessoas deveriam poder cantá-lo na língua que quisessem, se é que quisessem cantá-lo. A questão é: “¿todavía es el himno de la nación? ¿Puede ayudar a desmontar el nacionalismo? Creo que es una pregunta abierta para la que no tengo respuesta". O cantar do hino, como uma atitude de contradição performativa, poderia profanar a própria nação, tirando-a da sacralidade à qual foi remetida pelas fronteiras imunizatórias da Modernidade, e devolvendo-a ao uso do povo, para que este, a partir de sua pluralidade, se aproprie do termo e o ressignifique, ressignificando também todas as cesuras representadas pelas fronteiras que hoje aprisionam o sentido da humanidade.

\section{Conclusão}

Nosso tempo é inegavelmente marcado por travessias e deslocamentos. Seja de corpos ou de almas obrigados a desterritorializarem-se e re-territorializarem-se, em um mundo marcado por fronteiras que definem Estados ao mesmo tempo em que os cindem a partir das diversas nações que se constituem dentro deles. Enquanto vidas abjetas, contidas ou expulsas, são como restos, como lixo: desde os milhões conduzidos por trens aos campos de concentração nazistas aos contingentes de refugiados, banidos, imigrantes forçados pelas guerras pós-modernas e suas limpezas étnicas, passando pelos "sem papéis" que povoam as metrópoles, se é que não tenham terminado antes no fundo do mar, o mundo parece ter se tornado um turbilhão influxo, comportando multidões à deriva que margeiam as fronteiras que dividem o espaço territorial mundial, sejam elas territoriais, simbólico-culturais ou subjetivas. A partir dessas figuras, simbolizadas no refugiado, sejam aqueles banidos para além das fronteiras, seja os aprisionados dentro delas, sem direitos nem garantias, enquanto vidas que não merecem serem vividas, é que urge a necessidade de revisão das categorias centrais da filosofia política moderna. 
Há mais de setenta anos, Hannah Arendt já fazia essa advertência, provocando uma verdadeira ruptura na filosofia política e na teoria dos direitos humanos. Era necessário desvincular os direitos da humanidade das fronteiras do Estado-nação, ou o declínio de um (evidente em um mundo globalizado) iria necessariamente significar o declínio de outro. Quem irá proteger e garantir os direitos de cada ser humano? Há direitos para a humidade, ou melhor, há humanidade para além das fronteiras (físicas ou simbólicas) do Estado-nação?

Tais questionamentos ecoam em nossos ouvidos até hoje, e apesar de terem fundamentado a construção de um arcabouço "global" de proteção dos direitos humanos, como afirma a doutrina tradicional, os fatos atuais têm demonstrado nosso total fracasso e incapacidade de sequer encarar tal problema nos termos necessários. Agamben nos faz este alerta, e clama a que, se quisermos estar à altura das tarefas absolutamente novas que estão diante de nós, temos que nos decidir a abandonar sem reservas os conceitos fundamentais com os quais até o momento representamos os sujeitos do político (o homem, o cidadão, os direitos, o Estado, as fronteiras) e a reconstruir nossa filosofia política a partir de então.

A este chamado de cunho arendtiano feito por Agamben, Judith Butler parece procurar responder.A partir de sua filosofia pós-estruturalista e dos estudos em gênero, coloca em cena as vidas abjetas, aquelas que não se adaptam aos padrões normativos vigentes e, portanto, estão excluídas da condição de cidadania e de humanidade, tanto fora como dentro das próprias fronteiras do Estado-nação. A tentativa apresentada por Butler é a de pensar vínculos de humanidade e reconhecimento que estejam para além das fronteiras do Estado, levando esse Estado a se libertar do grilhão que o vincula à nação (supostamente heterogênea). Libertar o Estado da nação, des/re-construir, deslocar suas fronteiras (físicas, simbólicas ou culturais) de modo a abarcar a humanidade presente nas mais diversas nações que existem dentro dele (enquanto vínculos de identidade e pertencimento) é seu objetivo.

Se sua tentativa é bem sucedida, ou não, não nos cabe julgar. $O$ que nos cabe aqui é de forma singela contribuir com essa tarefa. Seja 
profanando, seja des/re-construindo performaticamente, precisamos com urgência nos desacomodar e buscar novas formas de reencontrar os vínculos de humanidade perdidos nas fronteiras do Estado-nação.

\section{Referências}

AGAMBEN, Giorgio. Política do exílio. In: DANNER, Leno; DANNER, Fernando (Org.). Temas de Filosofia Política Contemporânea. Porto Alegre: Fi, 2013. p. 33-50.

AGAMBEN, Giorgio. Meios sem fim: notas sobre a política. Belo Horizonte: Autêntica, 2015.

AGAMBEN, Giorgio. Profanações. Trad. Selvino J. Assmann. São Paulo: Boitempo, 2007.

ARENDT, Hannah. Origens do totalitarismo. São Paulo: Companhia das Letras, 2006.

ARENDT, Hannah. Origens do totalitarismo: antissemitismo, imperialismo, totalitarismo. Tradução Roberto Raposo. São Paulo: Companhia das Letras, 2013.

ARENDT, Hannah. A condição humana. Rio de Janeiro: Forense Universitária, 2010.

ARENDT, Hannah. Sobre a revolução. São Paulo: Companhia das Letras, 2011.

ARNAIZ, Graciano González R. La condición de extranjero del hombre (Apuntes para una ética de la diferencia). LOGOS: Anales del Seminário de Metafísica, Madrid, v. 32, p. 121-141, 1998.

BOURDIEU, Pierre. Prefácio. In: SAYAD, Abdelmalek. A imigração ou os paradoxos da alteridade. São Paulo: Edusp, 1998.

BUTLER, Judith. Bodies that matter: on the discursive limits of sex. New York: Routledge, 1993.

BUTLER, Judith. Fundamentos contingentes: o feminismo e a questão do "pós-modernismo". Cadernos Pagu, Campinas, n. 11, p. 11-42, 1998. 
BUTLER, Judith. O limbo de Guantánamo. Novos Estudos. Centro Brasileiro de Análise e Planejamento - CEBRAP, São Paulo, n. 77, p. 223-231, mar. 2007.

BUTLER, Judith. Vida precária: el poder del duelo y la violencia. Buenos Aires: Paidós, 2009.

BUTLER, Judith. Problemas de gênero: feminismo e subversão da identidade. 3. ed. Rio de Janeiro: Civilização Brasileira, 2010.

BUTLER, Judith. Vida precária. Contemporânea: Revista de Sociologia da UFSCar, São Carlos, n. 1, p. 13-33, 2011.

BUTLER, Judith; SPIVAK, Gayatri. Quién le canta al Estado-Nación? Buenos Aires: Paidós, 2009.

CANÇADO TRINDADE, Antônio Augusto. Prefácio: O Acesso Direto dos Indivíduos à Justiça Internacional. In: Manual de direitos humanos internacionais: acesso aos sistemas global e regional de proteção dos direitos humanos. São Paulo: Loyola, 2002. p. 15-22.

ESPOSITO, Roberto. Biopolítica y filosofía. Buenos Aires: Grama Ediciones, 2006.

ESPOSITO, Roberto. Bios: biopolítica e filosofia. Lisboa: LDA, 2010.

ESPOSITO, Roberto. Comunidade e Violência. In: DANNER, Leno; DANNER, Fernando (Org.). Temas de Filosofia Política Contemporânea. Porto Alegre: Fi, 2013. p. 13-32.

FERREIRA, Carlos Enrique Ruiz. O imigrante como um subversivo prático-político, possibilidade de um "novo mundo" - o projeto universal-cosmopolita dos Direitos Humanos em contraposição à Soberania territorial. Revista Emancipação, Ponta Grossa, v. 11, n. 2, p. 253-266, 2011.

FOUCAULT, Michel. Em defesa da sociedade. São Paulo: Martins Fontes, 2000.

GADAMER, Hans-Georg. Fenomenologia, hermenêutica e metafísica In: GADAMER, Hans-Georg. Hermenêutica em retrospectiva:

A virada hermenêutica. Tradução de Marco Antônio Casanova.

Petrópolis: Vozes, 2007. v. II. p. 73-80. 
GIACOIA JUNIOR, Oswaldo. Sobre direitos humanos na era da biopolítica. Kriterion: Revista de Filosofia, Belo Horizonte, n. 118, p. 267308, 2008.

GUIMARÃES, Helena. O elogio das aparências: Hannah Arendt e a crítica aos Direitos Humanos. Direito, Estado e Sociedade, Rio de Janeiro, n. 43, p. 10-39, 2013.

KRISTEVA, Julia. Estrangeiros para nós mesmos. Trad. Maria Carlota C. Gomes. Rio de Janeiro: Rocco, 1994.

LAFER, Celso. A reconstrução dos direitos humanos: a contribuição de Hannah Arendt. Revista Estudos Avançados, São Paulo, v. 11, n. 30, p. 55-65. maio-ago. 1997.

LAFER, Celso. A reconstrução dos direitos humanos: um diálogo com o pensamento de Hannah Arendt. São Paulo: Companhia das Letras, 1999.

PIOVESAN, Flávia. Direitos humanos e o direito constitucional internacional. 4. ed. São Paulo: Max Limonad, 1997.

PRINS, Baukje; MEIJER, Irene Costera. Como os corpos se tornam matéria: entrevista com Judith Butler. Estudos Feministas, Florianópolis, v. 10, n. 1, p. 155, jan. 2002. Disponível em: <https://periodicos.ufsc.br/index.php/ref/article/view/S0104026X2002000100009/8771>. Acesso em: 26 nov. 2015.

SCHMITT, Carl. Teoria de la constituición. Trad. Francisco Ayala. Salamanca: Alianza Editorial, 2006.

Recebido em: 24/02/2016

Aprovado em: 06/03/2017 